\title{
Social Institutional Influence on Fisheries in Two Fishing Communities in the Volta Lake in Ghana
}

\author{
Marian Adwowa Amu-Mensah1, Frederick K. Amu-Mensah1, Edward K. Abban² \\ ${ }^{1}$ Council for Scientific and Industrial Research (CSIR), Water Research Institute (WRI), Accra, Ghana \\ ${ }^{2}$ Intelligence Nature International (INI), Accra, Ghana \\ Email: baarbs92@hotmail.com, fkamu.mensah@csir-water.com, kofi_abban@yahoo.co.uk
}

Received 1 July 2014; revised 9 August 2014; accepted 22 August 2014

Copyright (C) 2014 by authors and Scientific Research Publishing Inc.

This work is licensed under the Creative Commons Attribution International License (CC BY).

http://creativecommons.org/licenses/by/4.0/

(c) (i) Open Access

\begin{abstract}
Social institutions are one of the most important institutions in communities, especially in rural areas, where decision making depends on the chief, his elders or opinion leaders in the community. The study looked at the hindrances and catalysts they presented, to the introduction of an innovation (fish cage culture) and its acceptance. The paper, presents how Dzemeni and KpandoTorkor, fishing communities in the Volta Region, are influenced by their social institutions in fisheries activities. Using primary and secondary data, the study investigated the potential of social institutions influence and possible effect on fishery innovation. Results indicated that institutions with better capacities mostly influenced individual and community decisions on livelihood activities. Influence, is in the form of financial support, advice and availability of the right infrastructure, to promote fishery development. It was evident that there were variations in influence and support of the social institutions and differences in the impact between the two communities. The study recommends that, fishery innovations and growth opportunities should be mainstreamed into the maintenance of social institutions or traditional knowledge, in the diffusion of new technologies, for sustainable fishery development.
\end{abstract}

\section{Keywords}

Social Institutions, Influence, Diffusion, Fishery Innovation, Cage Culture, Volta Lake

\section{Introduction}

In general, countries with well-developed social institutions have greater adaptive capacity than those with less effective institutional arrangements to support or impact on development activities (Smith \& Lenhart, 1996).

How to cite this paper: Amu-Mensah, M. A., Amu-Mensah, F. K., \& Abban, E. K. (2014). Social Institutional Influence on Fisheries in Two Fishing Communities in the Volta Lake in Ghana. Sociology Mind, 4, 305-316.

http://dx.doi.org/10.4236/sm.2014.44031 
Anderson (1997) explains that these activities of the social institution generally centre on the family, education, economy, polity, and religion. Literature review indicates that social institutions are the normative structures that get main work done within the society.

Lakes are one of the most important natural resources especially in West Africa and beyond. They provide highly productive resources in fishery (Mensah et al., 2006; Braimah, Sarfo-Mensah, \& Kunu 2003; World Bank, 2004). In providing practical approaches to fishery development and fish productivity, the ability of the fishing communities to cope with introduction of an innovation is very important to the diffusion of any new fishery technology (Rogers, 1995; Brown, 1981). In multicultural communities like the riparian communities of the Volta Basin, where fisheries have been under development for several years (Braimah et al., 2003), decision makers need to understand the impact of the social systems of beliefs, knowledge, values and traditions. These social institutions influence the thinking and decision making processes involved in the use of resources, whilst ensuring equity in their use Lenselink (2002), and Apu \& Middendrop (1998), which in effect, can affect the diffusion of a new technology in all surrounding communities. O'Riordan and Jordan (1999), explained that social institutions were "... means for holding society together, giving it sense and purpose, and enabling it to adapt”.

Since 1968, there have been efforts by the Ghana government to develop fisheries in the riparian communities of the Volta Lake. Most of these projects took off without much consideration to the possible influences or the contributions of social institutions (Asafo, 1999). According to Chambers (1970), social and administrative problems encountered by the Volta basin resettlement program constituted lack of social cohesion, differences in spoken dialects and mannerisms, political rivalry between chiefs and rural systems of allegiance to tribal chief. The problem is whether social institutions have any significant impact or influence on fishery activities. It is therefore necessary to understand the dynamics of the social institutions before the introduction of an innovation to ensure the acceptance of the innovation (Lenselink, 2002).

Fish cage culture, a new method for growing fish in large reservoirs or lakes is being introduced to the Dzemeni and Kpando-Torkor communities, around the Lower Volta Basin. Fish cage culture utilizes existing bodies of water such as dams, rivers, lakes, bays, reservoirs and coves but encloses the fish. This is one of the effective technologies used in raising tilapia. It started out in 1974 in Sampaloc Lake and Laguna Bay and the wildly spread practice is found in different regions like in Magat Dam Reservoir in Region II, Egypt, India, and in most parts of Asia. The integrity of the cage unit means that large, communal water bodies have the crucial ability to culture (Masser, 1988). By applying the concept of acceptance of innovation, as discussed by Rogers (1995), that the authority of social institutions or few individuals in the system who possess power, status or technical expertise can influence the choices of a community. The paper focuses on how social institutions like family, religion, education, health, economy (fishery industry) in the two selected communities, can influence or impact positively or negatively on cage culture acceptance or diffusion. To answer this question, the paper examined the activities of the social institutions in relation to fishery related activities and how the institutions influenced their activities. The paper also tries to explain what constraints and opportunities the social structures present in order to take advantage of the institutions, to help further the sustainable development of the fisheries industry. Similar studies conducted in the Philippines and Tanzania by Uwe et al. (2001) show an increase in fishers, due to the ability of the support of social institutions to take advantage of new improved opportunities and other changes in infrastructure. This has led to more occupational shifts into fishing from other sectors of the rural communities.

The theoretical perspective is based on the fact that the performance or potential of the diffusion of an innovation in a society as a whole is dependent on the social institutions in ensuring its survival and growth. Some customs and beliefs to some extent influence the way fishers go about their fishing or economic activities. According to Amu-Mensah (2007) new patterns of morality and systems of norms, social rules which are less rigidly enforced could affect the acceptance of the cage culture negatively. Durkheim (1893) explained that such weaknesses in the social systems were dangerous to society, if the individual's desire and ambitions were not in line with the general moral code of conduct. Nevertheless, Max (1971) as cited in Webster (1988) believed that it was the best feature of a community for efficient market relationships. This helps to promote economic development, because division of labour and diversity of ideas in this case helps with capital investment.

The choice to adopt or reject an innovation could be possible, through consensus among the members of a community. An example is in situations where the chief enforces laws concerning fishing days, and there is consensus to adhere to the regulations by all fishers or not to. These restrictions according to Irvine (1947) do 
not harm anyone, but it could be very beneficial in the process of the Lake revitalising its self. Religious practices, perceptions of the spirit world and notions of magic, as well as detailed observation of the environment may all play a role in the impact of social institutional influences (Senah, 1997: p. 104). Beliefs of people also affect attitudes towards the ability to accept an innovation in a diffusion process. Social institutional influence on innovation backed by research findings had been appreciated over a considerably long period. They have influenced the incorporation of technology in activities and issues pertaining to livelihood.

Dzemeni is in the South Dayi district, a newly created district which lies within latitudes $3^{\circ} 20 " \mathrm{~N}$ and $3^{\circ} 35 " \mathrm{~N}$ and approximately on longitude $0^{\circ} 17$ "E. The Volta Lake forms the western boundary. Kpando-Torkor is to the north of Dzemeni with Ho in the east and the Asuogyaman District to the south. The language spoken is Ewe (South Dayi, 2006; Kpando, 2005).

Figure 1 gives an indication of the study area. Dzemeni and Kpando-Torkor, major fish landing sites in the Volta Region, are settlements along the riverbanks of the Volta. Fishers in the area depend mostly on the water body as their source of income and livelihood. Figure 2 shows a typical market day in the communities.

The total populations of Dzemeni and Kpando-Torkor according to the 2010 population and housing census of Ghana are 4234 and 3399 for the areas respectively, with an average per capita income of US \$372, (CGIAR, 2004). The major economic activities are fishing, processing of fish, selling of fish to other parts of the Volta, Eastern and Greater Accra Regions and beyond the boundaries of Ghana by cargo trucks.

The objectives of this paper was to look at the nature of social institutions and their influence in fisheries related activities of two major fishing communities, to examine fishers' perception of social institutional influence in increasing fisheries productivity and to document the capabilities of existing social institutions.

\section{Research Methods}

The study population was fishers, opinion leaders in fishery, heads of institutions representing identified social institution. The sampled size was 172 fishers representing the total population of the two homogeneous fishing communities, based on sample generalization. Respondents for the quantitative data were randomly selected from the various associations in the two communities, whiles purposive sampling was used to select respondent for the qualitative study. Primary data were obtained through interviews, Focus Group Discussions, and questionnaire administration. Semi-structured and structured questionnaires were administered, in the two communities to obtain information on how social institutions influence fisheries related livelihoods in the area of study.



Figure 1. Study areas of Dzemeni and Kpando-Torkor. Source: field survey (GPS locations). 


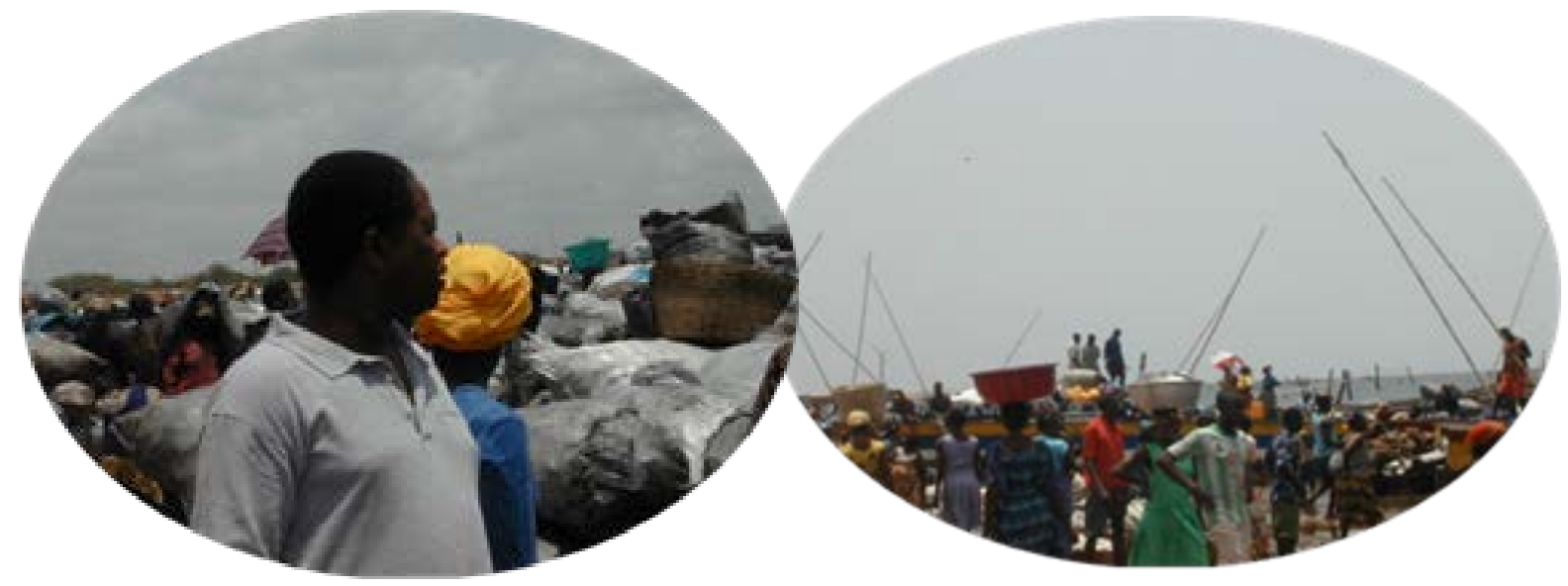

Figure 2. Economic activities on the banks of the lake. Source: field survey.

Literature review touched mainly on the nature, functions as well as the historical trends of social institutions oninnovation diffusion in riparian communities. In addition, fishers' knowledge and perception of the social institutions' capabilities were documented using in-depth interviews and focus group discussions as well as structured and semi structured questionnaire. Focus Groups Discussions were conducted in collaboration with researchers on the Challenge Program CP-34 project in both communities. The combination of research techniques, in collecting data facilitated and reduced biases as well as socially undesirable answers whilst limiting errors in the data collection for analyses.

One-way analysis of variance (ANOVA) was used to determine whether there are any significant differences between the means of two or more independent (unrelated) groups. An independent t-test was conducted using Levene's Test for Equality of Variances, to test the differences in effect between the two communities. This was to find out if social institutions with better capacities could have significant influence on individual and community decisions on fisheries related livelihoods.

\section{Results}

\subsection{Characteristics of the Respondents}

Respondents were aged between 15 to 64 years, with $54 \%$ between the ages of 35 to 44 , looking at the cross tabulation in Table 1, majority of the respondents in both age groups are between the ages of 35 to 44, signifying the active group engaged in fishing.. The data also explains the number of female or males working in the fishery sector. Respondents explained that most women age less than 34 were either are in school, into other businesses or not interested in the fishing business. Respondents also explained that most of young are busy taking care of their young ones or siblings.

During a focus group discussion, some opinion leaders explained that the hard and difficult environment requires a person with the right wits and skills to keep the family going. Daily challenges require continuous and numerous quick decisions as well as the need for a good commercial mind. Standards of living are different; some of the poor and elderly depend on menial jobs like scaling of fish, running errands for the extended families to be able to earn something for their daily bread, whilst others depend on the larger extended family or religious bodies for livelihood support or survival.

From the data it could be concluded that the male retire from the fishery sector much early than the women, this according to the respondent was due to the nature of their work. The active and strong group formed the majority. Majority of the fishers interviewed were married and living with their spouses.

\subsection{Influence of Social Institutions on Fishery Related Activities}

According to Anderson in the literature review, social institutions are the structures that get work done within society. Research has shown that all these institutions go a long way to create the enabling environment for the acceptance or rejection of an innovation. The analysis of social institutions influence in the two selected com- 
munities looks at the most possible influential of social institutions, in the acceptance of innovation. In addition, it also examined the kind of impact or influence the social institutions have. The study tries to determine if there are variations, in the influences of social institutions on fishery related activities.

\subsection{Descriptive Data for the Social Institutions}

\section{Assumptions}

1) The populations from which the samples were obtained are normally or approximately normally distributed.

2) The samples from the k populations are independent.

3) The variances of the populations are equal (homogeneity of variance).

4) The level of measurement is at least an interval scale.

From the data in Table 2, religion has the most influence or impact on fishery activities; this is followed by health and the economy which is represented by the fishery institution, with the least impact as the working colleagues' institution.

Table 1. Age \& gender cross tabulation of respondents $(n=172)$.

\begin{tabular}{|c|c|c|c|c|c|c|}
\hline \multirow{2}{*}{$\begin{array}{c}\text { Item } \\
\text { Age }\end{array}$} & \multicolumn{4}{|c|}{ Category } & \multirow{2}{*}{ Frequency } & \multirow{2}{*}{ Percentage } \\
\hline & Group & $35-44$ & $45-55$ & $56+$ & & \\
\hline \multirow[t]{2}{*}{ Gender } & Male & 61 & 20 & 0 & 101 & 58.6 \\
\hline & Female & 32 & 14 & 20 & 71 & 42.4 \\
\hline \multirow[t]{2}{*}{ Totals } & 25 & 93 & 34 & 20 & 172 & 100 \\
\hline & \multicolumn{3}{|c|}{ Marital status } & & Frequency & Percentage \\
\hline \multicolumn{5}{|c|}{ Single } & 15 & 8.4 \\
\hline \multicolumn{5}{|c|}{ Married and living with spouse } & 118 & 68.6 \\
\hline \multicolumn{5}{|c|}{ Married and living with parents } & 5 & 3.0 \\
\hline \multicolumn{5}{|c|}{ Married and living alone } & 17 & 10.0 \\
\hline \multicolumn{5}{|c|}{ Divorced } & 17 & 10.0 \\
\hline \multicolumn{5}{|c|}{ Totals } & 172 & 100 \\
\hline
\end{tabular}

Table 2. Descriptive stats for social institutions (both communities).

\begin{tabular}{|c|c|c|c|c|c|c|}
\hline & \multirow{2}{*}{$\mathrm{N}$} & \multirow{2}{*}{ Mean } & \multirow{2}{*}{ Std. dev } & \multirow{2}{*}{ Std. err } & \multicolumn{2}{|c|}{$95 \%$ CI for mean } \\
\hline & & & & & L bound & U bound \\
\hline Family & 70 & 3.9857 & 0.80744 & 0.09651 & 3.7932 & 4.1782 \\
\hline Religion & 70 & 4.4000 & 0.76896 & 0.09191 & 4.2166 & 4.5834 \\
\hline W. colleagues & 70 & 3.3429 & 1.15327 & 0.13784 & 3.0679 & 3.6178 \\
\hline T. authorities & 70 & 3.6571 & 1.30646 & 0.15615 & 3.3456 & 3.9687 \\
\hline Health & 70 & 4.2857 & 0.98013 & 0.11715 & 4.0520 & 4.5194 \\
\hline Assembly man & 70 & 4.0857 & 1.01785 & 0.12166 & 3.8430 & 4.3284 \\
\hline F. institution & 70 & 4.2714 & 0.91559 & 0.10943 & 4.0531 & 4.4897 \\
\hline E. institutions & 70 & 4.0000 & 1.06322 & 0.12708 & 3.7465 & 4.2535 \\
\hline Total & 560 & 4.0036 & 1.06160 & 0.04486 & 3.9155 & 4.0917 \\
\hline
\end{tabular}

Source: author's fieldwork, 2009. 


\subsection{Analysis of Variance in Social Institution}

Table 3 displays the analysis of variance for testing whether there are significant differences in the impact or influence of social institutions on fishery activities in the community. The result indicates significant differences $(\mathrm{F}=8.462 ; p=0.000 \leq 0.05$ ) between the impacts of the various social institutions on fishery related activities. It can be concluded that the differences noticed in the impacts made by the various social institutions are not by chance.

\subsection{Significant Differences in the Impact of Social Institutions}

An independent t-test was carried out, to test for significant differences in the impact or influence of social institutions on fishery activities in the two communities (i.e. Dzemeni and Kpando-Torkor). From Table 4, there are significant differences in the impacts of the various social institutions on fishery activities between the two communities. In all cases, the effect or impact of the social institution was greater in the Dzemeni community than as compared to the Kpando-Torkor community. This is evident in the positive mean different values shown on Table 5 .

Table 3. ANOVA table for the whole data (both communities).

\begin{tabular}{cccccc}
\hline Source of variation & Sum of squares & df & Mean of square & F & Sig. \\
\hline Between groups & 61.050 & 7 & 8.721 & 8.462 & 0.000 \\
Within groups & 568.943 & 552 & 1.031 & & \\
Total & 629.993 & 559 & & & \\
\hline
\end{tabular}

Source: author's fieldwork, 2009.

\section{Table 4. Independent t-test for effect in the communities.}

\begin{tabular}{|c|c|c|c|c|c|c|c|}
\hline & & \multicolumn{3}{|c|}{ Levene's test for equality of variances } & \multicolumn{3}{|c|}{ t-test for equality of means } \\
\hline & & $\mathrm{F}$ & Sig. & $\mathrm{t}$ & df & $\begin{array}{c}\text { Sig. } \\
\text { (2-tailed) }\end{array}$ & $\begin{array}{c}\text { Mean } \\
\text { difference }\end{array}$ \\
\hline \multirow{2}{*}{ Family } & Eq. variance & 0.125 & 0.725 & 4.619 & 68 & $0.000^{*}$ & 0.79167 \\
\hline & Non equal variances & & & 4.585 & 60.827 & 0.000 & 0.79167 \\
\hline \multirow{2}{*}{ Religion } & Eq. variance & 6.677 & 0.012 & 2.617 & 68 & 0.011 & 0.46667 \\
\hline & Non equal variances & & & 2.470 & 47.116 & $0.017^{*}$ & 0.46667 \\
\hline \multirow{2}{*}{ W. colleagues } & Eq. variance & 1.441 & 0.234 & 2.447 & 68 & $0.017^{*}$ & 0.65833 \\
\hline & Non equal variances & & & 2.358 & 52.730 & 0.022 & 0.65833 \\
\hline \multirow{2}{*}{ T. authority } & Eq. variance & 1.714 & 0.195 & 3.078 & 68 & $0.003^{*}$ & 0.91667 \\
\hline & Non equal variances & & & 2.999 & 55.803 & 0.004 & 0.91667 \\
\hline \multirow{2}{*}{ Health } & Eq. variance & 3.837 & 0.054 & 3.953 & 68 & 0.000 & 0.85000 \\
\hline & Non equal variances & & & 3.756 & 48.864 & $0.000^{*}$ & 0.85000 \\
\hline \multirow{2}{*}{ Assembly man } & Eq. variance & 19.080 & 0.000 & 3.468 & 68 & $0.001^{*}$ & 0.79167 \\
\hline & Non equal variances & & & 3.238 & 44.327 & 0.002 & 0.79167 \\
\hline \multirow{2}{*}{ F. institutions } & Eq. variance & 0.834 & 0.364 & 2.806 & 68 & $0.007^{*}$ & 0.59167 \\
\hline & Non equal variances & & & 2.747 & 57.230 & 0.008 & 0.59167 \\
\hline \multirow{2}{*}{ E. institutions } & Eq. variance & 7.063 & 0.010 & 2.094 & 68 & $0.040^{*}$ & 0.52500 \\
\hline & Non equal variances & & & 1.992 & 49.152 & 0.052 & 0.52500 \\
\hline
\end{tabular}

Source: author's fieldwork, 2009 (significant difference at 5\% level of significance). 
Table 5. Statistics for the effect of social institutions by community.

\begin{tabular}{cccccc}
\hline & Respondent community & $\mathrm{N}$ & Mean & Std. deviation & Std. error mean \\
\hline \multirow{2}{*}{ Family } & Dzemeni & 40 & 4.3250 & 0.69384 & 0.10971 \\
& Kpando-Torkor & 30 & 3.5333 & 0.73030 & 0.13333 \\
Religion & Dzemeni & 40 & 4.6000 & 0.59052 & 0.09337 \\
& Kpando-Torkor & 30 & 4.1333 & 0.89955 & 0.16424 \\
Work colleagues & Dzemeni & 40 & 3.6250 & 0.97895 & 0.15478 \\
& Kpando-Torkor & 30 & 2.9667 & 1.27261 & 0.23235 \\
Traditional authority & Dzemeni & 40 & 4.0500 & 1.13114 & 0.17885 \\
& Kpando-Torkor & 30 & 3.1333 & 1.35782 & 0.24790 \\
Health & Dzemeni & 40 & 4.6500 & 0.73554 & 0.11630 \\
Kpando-Torkor & 30 & 3.8000 & 1.06350 & 0.19417 \\
Assembly man & Dzemeni & 40 & 4.4250 & 0.71208 & 0.11259 \\
& Kpando-Torkor & 30 & 3.6333 & 1.18855 & 0.21700 \\
\hline
\end{tabular}

Source: author’s fieldwork, 2009.

Finding answers to some of the discussions, on the perception of fishers, respondents gave their views on social institutions. The variations in their responds, according to respondents are due to the kind and extent of support and advice they obtain from the institutions. Some of the influences of the social institutes are explained by the respondents in the next passage.

\subsection{Perception of Social Institutional Influence}

An in-depth interview and a focus group discussion revealed that, marriage brings different families together and in most riparian communities, the family controls economic production, with the man as the head of the family and the owner of the business. Some respondents indicated that women were the owners of fishing business, as well as money lenders to fishers. Despite the flexible nature of the fishery business for both gender it came to light that there is a taboo, preventing women during a period in their life's cycle, from entering the Volta Lake although it is the biological nature of women to menstruate. Respondents in Dzemeni indicated that most family members advance money to their relations, who need money to start a business or to expand their fisheries business. This is one way in which fishers borrow money to invest in their business there by influencing the direction of the borrower's decision. According the fishers it is difficult to borrow from the banks which are not easy to access and also have high lending rates. In situations where family members provide the sources of finance, the fishers indicated it can influence the thinking and decision making process since they would have to listen to the advice of their financier. This kind of influence can extend to the acceptance and diffusion of fishery cage culture among fishers.

Opinion leaders and nurses from the various communities interviewed explained that, clinics and maternity homes are not adequate due to the number of people who come to the communities to do business and the growing population. Most fishers interviewed indicated that, the health institutions is a very important institution in the community although government does not consider the constraints fishers go through in accessing healthcare, considering the inadequacy of health infrastructure, access to financial services and information dissemination in the health sector. 
Some of the ailments affecting fishers they indicated cannot be treated in the clinic and therefore they have to travel some distances to get treatment from the district hospitals. This means spending several man hours away from their fishery activities and losing the revenue they could have earned during that period. Fetish heads are considered to be powerful healers and versatile in traditional medicine. The fishers explained that diseases like swollen feet, snakebites, high fever or mental problems, and sometimes stomach problems can be treated easily by the traditional herbalist. The clinic or the major hospitals, handle issues like malaria, fevers, headaches and difficulties in childbirths. Nurses who have worked for several years in the communities and are quite experienced operate the clinics without a doctor. The entirety of the medical staff or health personnel's in both communities come to seven in Dzemeni and nine in Kpando-Torkor. Health plays a very important role in the lives of fishers. Sick and weak fisher-folks according to respondents, cannot be productive enough to support any innovation or fisheries business venture there by influencing fishery activities. The state of such an unhealthy person or people will not encourage or allow the fisher to give off their best and this will greatly influence the fishers' capability to work effectively to support an acceptance to increase fish productivity. Such situations can put the diffusion of cage culture and its sustainability in danger especially when there is an outbreak of a disease and the available health facilities cannot handle the situation.

In-depth interviews with religious leader revealed that there are different religious groups and they all exist harmoniously with each other during communal labour. According to the chief of Dzemeni, the religious institutions come together to participate in communal labour, provide streetlights through donations from church members. Religious bodies also participate in other developmental activities in the area which goes to enhance the operations of their fisheries activities. Most churches in both study area offer financial support to the needy, the sick and the old and the priests use the pulpit to advice fishers in their fisheries businesses. This manner of preaching according to the fishers, compel them to try to lead honest life, which helps to ensure harmony among the fishers. This is an indication of a positive sign of coordination, which any diffusion of technology would need for a successful increase in fisheries productivity. The advice and warnings from the priest based on the beliefs of the fishers' can also affect the mind set and attitudes, towards the ability to accept an innovation for diffusion process. An in-depth and focus group discussion showed that Traditional Religion and some spiritual churches provide assistance to the communities health-wise, through prayers and healing of the sick. Other orthodox and Christian institutions assist the community with schools, as well as the provision of health facilities to ensure the good health of the fishers. Collaboration and inter-relationship between the religious and health institutions are established with the provision of health facilities. There is also an inter-relationship either between the family and religion, where poor families or the underprivileged in the community receive assistance through the direct contributions of other family members or through the church. A custom, which seeks the support of the gods in increasing fish supply in the lake, is performed on every Thursday of the first week in March, very early in the morning at the Lake side. Religious practices do not harm anyone but are very beneficial in the process of revitalization of lake when it comes to indigenous rules and regulations governing the lake. Sometimes, the mere mention of a new technology by the pastor, a family head or the traditional authority would encourage community member to seek more knowledge in the innovation. In certain instances, infrastructure, financial support and advice provided by the church can also influence the fisher in an innovation if the church is directly involved on the innovation process. Results from the Table 6, indicates that fisher are influenced by the most important people and social institutions in their life, as individuals and the community as a whole on decisions pertaining to livelihood.

Some fishers believe that, education brings into the community civilization and development. This helps to develop their human resources, to be able to raise their level of understanding of issues better, to cope with new things. Some of the fisher-folks said education influences them to manage their finances very well, thus helping to improve on their fisheries businesses. Some respondents believe education helps them to improve on their methods of fishing and fish processing, to sustain and develop fisheries resources. Although teaching the child the families' trade is part of the socializing attributes of the riparian communities, family members can only obtain assistance from their children when school is on recess. This means that they will have to pay to train other people to assist in their fisheries businesses as well as pay for their children's school fees thereby increasing the amount of money they can put into their fishery business.

Through an in-depth interview, it came to light that the chief of Dzemeni fishing community, Togbe Teffutor Orko II, is very much involved in ensuring that, rules and regulations governing the use of the Volta Lake near his community are adhered to. As the head of the Traditional Authority, he also ensures the adherence and the 
Table 6. Individual/social institutional influence.

\begin{tabular}{ccc}
\hline Individual/social institutional influence & Frequency & Percent \\
\hline Not at all & 3 & 4.3 \\
No & 2 & 2.9 \\
Don't know & 7 & 10.0 \\
Very & 25 & 35.7 \\
Very much & 27 & 38.6 \\
Not sure & 6 & 8.6 \\
Total & $\mathbf{7 0}$ & $\mathbf{1 0 0 . 0}$
\end{tabular}

Source: author's fieldwork, 2009.

maintenance of law and order in the community. He travels on international fisheries conferences because he needs the necessary information on fisheries, to be able to help sustain the livelihood of his community. The above information, confirms the data in the hypothesis on the influence of social institution in Dzemeni.

The fishers explained that most of the government institutions related to fishery development do not deal directly with the fisher-folks. Development plans and the development of the riparian communities are executed through their officers at the national or district level. The plans are then handed down at different levels of the government institutions and departments until it gets to the fishers, thus creating a communication barrier where first-hand information never gets to them.

Opinion leaders and the chief of Dzemeni explained that, almost all the Dzemeni settler fishers under the Dzemeni chief adhere to traditional rules governing the people in the community. This is so because the various headmen of the different ethnic groups form the community elders, or the council of elders are the chief's advisors. However, Togbe Teffutor Orko II believes that there has been an adulteration of norms and values and this has affected the methods of fishing ${ }^{1}$ Kpando-Torkor operates a different system. The chief fisherman in collaboration with the ethnic headmen, and not the chief, Togbe Ken Adom of Kpando-Torkor, is responsible for all fishing issues ${ }^{2}$. In Kpando-Torkor, members of the community, send most of their wrong doers in fishery related issues to the police station at Kpando the district capital and not to the chief, as it is in the cases of Dzemeni although they also have a police post in Kpeve the district capital. His situation is so because according to opinion leaders in the community because there is very little respect for the chief. This is supported by Table 5 , in the placement of traditional authority and the other institutions. In some cases the head of the ethnic groups try to deal with such issues, creating more room for conflicts especially when two ethnic group heads, do not want to compromise with each other. Most of the respondents representing 56 percent indicated that there were sanctions for those who flouted the rules and regulation on fisheries resources but it was not really enforced, 34 percent indicated that there were no sanctions. Indications were that enforcement of the rules is lax and therefore people can get away with offences but for the presence of police in the Kpando Township which is some few kilometres away from the Kpando-Torkor community.

Fishers indicated that, the economy helps to bring in jobs while assisting them to exchange goods and services through which the fishers are able to earn a living to feed their families. This they believe influences their income and capital to fish or trade in fishery. Some respondents said the economy creates the avenue for the easy disposal of their fishes and wares to people for income which is taxed to support developmental activities. These developments help to improve the needs of members of the community as well as visitors who come to buy and sell. Some also indicated that the prices of goods and fishing inputs are very high due to the price hikes in fuel. According to many of the respondents interviewed, it is difficult to earn a living or sustain their families since loans are not easy to come by and if secured, the interest rates are very high. Interest rate on loans ranges from 10 percent every week from moneylenders to 30 percent per annum by the banks. The "susu” system of saving money with a "Money collector" who helps you to accumulate money for a month or two, take a percentage of your saving and returns the rest to you, is not well developed as a source of capital. One of the complaints from

\footnotetext{
${ }^{1}$ Information supplied on 27th October 2009.

${ }^{2}$ Spoke to informant on the 29th October 2009.
} 
the fisher-folks was that the price of fish is unstable depending on the level of catch and this makes it difficult for fishers to maintain a fixed price to improve on their economic well-being. It can be concluded that the economic institution, does have a negative impact on the livelihood of fishers, considering the fact that prices are not stable to allow the fisher to plan their income and expenditure to make ends meet.

Data collected and analysed indicated that most fishers' decisions on livelihood are affected or influenced by the important people in their lives. They would listen and take the advice of people who are close to them or priests, nurses or their parents when they have to take important decisions, concerning occupation and money matters. Out of seventy respondents, the data indicates that few people were either not sure or unaffected, by people who are important to them. There are indications that, most of the fishers are likely be influenced by such people in their decisions, to take up the cage culture or not, thereby influencing the diffusion of cage culture in other communities.

\section{Discussions}

From the data there is an indication that most of the young members are in school and those above schooling age could be working outside the fisheries industry. According to Townsley (1998) where fisheries resources are on the decline, or access to fisheries is threatened, the society adjusts by placing priority on the education of the children so that they can move out of the sector more easily and thus sustain family livelihoods. Townsley, also indicated that within the family institution, skills and knowledge on fishing techniques and fisheries resources, in most cases are hand out from one generation to the next at the household level. It may well be that the art of socializing the young ones into the techniques of the family business is being lost to formal education. However it cannot be ruled out that the young ones still support their parents on vacation as was indicated by some respondents. The chief of Dzemeni emphasised this when he said, "We are fishers and we will continue to be fishers even after our university degrees".

The involvement of both men and women in the fishery sector is an indication that there are no strict rules or taboos to hold back any women within the study communities, in their participation in fisheries, or from becoming the owner of a fishery business. From the data in Table 1 it was obvious that majority of the respondents were married people living with their spouses, which according to Lenselink (2002), is a good indication for family support in fishery business. Through family ties, churches, fisher associations, traditional authorities, "Susu" groups and trade networks, fishers are able to develop their fishing business and access capital, on which depends the success of their fish trade confirming the observation by Lenselink (2002). There is evidence confirmed by the data analysed using the analysis of variance for testing whether there are significant differences in the impact or influence of social institutions, although not very strong in Kpando-Torkor confirming indications by respondents during the in-depth interviews and the t-test for differences in effect between the two communities.

Kpando-Torkor market was previously a part of a fisheries complex with fairly well developed infrastructure. At present almost all the infrastructure at the complex has deteriorated. There is an indication from the data analysed that, society is more fragmented towards their ethnic groupings in Kpando-Torkor as opposed to the situation in Dzemeni. There is anonymity in the society, possibly due to earlier developments in the community where there is a gradual increase in division of labour of the social institutions. With the passage of time, fishing activities as carried out has witnessed an increasing separation from centralisation to decentralisation. Development in an impoverished community can lead to alienation, giving an indication that institutions affected are less able to withstand the pressures of change (Webster, 1988). It is therefore not surprising that the social institutions in Kpando-Torkor have very little influence on fishery livelihood activities and the community remains poor despite the numerous economic development activities that have taken place. The situation in KpandoTorkor could also be attributed to the way in which development was introduced into the community without the direct involvement of the social institutions as indicated by the review. Whiles in Dzemeni, there are indications from data that the support and influence of its social institutions has helped with some development in the fishery sector. This shows that strong institutions can influence fisheries related developments.

Improved mechanisms should be put in place by stakeholders in government and the social institutions concerned, to check the price of fishery resources and the unstable pricing of fish thus helping to reduce loss of income in the fish trade. Such coordination from government and traditional institutions can ensure the sustain- 
ability and maintenance of the fishery resources (Butler, 1997). There is also an indication that institutions such as the religion, health and, family influence fishery related issues through their support and advice of fishers, whiles the economic institution which is one of the most important institution influences through the mechanism to generate income. This kind of influence helps to control fishers' decisions making processes which will eventually control the acceptance of an innovation to increase fish production whether positively or negatively. Inadequate health facilities also influence the strength and capability of a fisher to work let alone support in fish cage culture to increase fish production. This needs to be improved.

\section{Conclusion and Recommendations}

Although the data show that strongest social institutions are the most influential, they are not the only factors that influence the diffusion of an innovation. The quality and knowledge of innovation also influence its adoption. Indications are that influence of some social institutions is mainly through advice, financial support and emotional support. It could be argued that our ability to innovate depends largely on two factors: the people, organizations and institutions in our society and our system of values and incentives and the ways they guide our behaviour, collectively and individually. It is, therefore, an issue of improved cultural or social institutional values and innovations in our source of livelihood that can make major contributions to our quality of life.

Based on the analyses the conclusion is that, social institutional influence on fishery resource use is significant although others are quite influential depending on their importance within the community. Social institutions contribute to development in communities by helping to organise family, faith, attitudes and rule of law, transfer of culture and traditional norms, mitigation and conflict resolution and sustainable use of the potential of their resources. Religion which was ranked first among the social institutions had an intense and significant influence, through their coercive abilities and financial support to very poor fishers.

The study shows variations in influence and support of some social institutions in both communities. Dzemeni from the data seems to be doing well with the support of its social institutions; meanwhile the social institutions in Kpando-Torkor community were not strong enough, to solicit very strong impacts on the community. Indications are that social institutions with weak capacities do not have the strong influence on innovation and the decision-making processes in the livelihood activities of the fishers.

The government and stakeholders in fishery need to pursue development policies designed to strengthen traditional institutions which can change the power structure to strengthen the role of these institutions, while spurring on fishery and economic developments. In the view of Butler (1997), this will improve its performance to positively influencing the diffusion of fishery innovation. Of particular importance are the large numbers of non-professional, often seasonal fishers who use their own innovative ways as a source, for feeding their families and providing livelihood activity during periods of slack agricultural labour demand. Nevertheless it is also important to maintain the environment and sustain natural resources from over exploitation through enforcement of laws on illegal fishing methods.

The appropriateness of the innovation for the exploitation of fishery resources should be assessed with reference to the fishers' ability to make use of the fishery innovation, in reducing poverty. It is important to mainstream social institutional rules and recommendations in fishery, into current scientific and practical approaches to fisheries management to ensure sustainable development. Since the study indicated that the backbone of the economic system in the area was fishing and related activities, fishery stakeholders should take steps to involve the heads of social institutions and opinion leaders who mattered in the development and economic wellbeing of fishers.

\section{References}

Amu-Mensah, M. A. (2007). The Capacities of Social Institutions to Cope with Fishery Innovation: A Case Study of Dzemeni and Kpando-Torkor, Fishing Communities in the Volta Basin. MPhil Sociology Thesis, Submitted to the School of Research and Graduate Study, Legon: University of Ghana.

Apu, N. A., \& Middendrop, H. A. J. (1998). Establishing Fisher Groups for Self-Management of Enhanced Fisheries in Semi-Closed Water Bodies. FAO Fisheries Technical Paper 374, 393-406.

Asafo, C. K. (1999). The Role of Fisheries Department of the Ministry of Food and Agriculture in the Volta Basin. In Gorden, \& Amatekpor (Eds.), The Sustainable Integrated Development of the Volta Basin in Ghana. Accra: Gold Type Press. 
Braimah, L. I., Sarfo-Mensah, P., \& Kunu, A. J. (2003). Institutions Influence on Policies-Sustainable Fisheries Livelihoods Programme (SFLP). Stakeholders for Inland Fisheries Co-Management Project Report, Ghana.

Brown, L. A. (1981). Innovation Diffusion: A New Perspective. Methuen Webber Journal, 30, 487-489.

Butler, S. M. (1997). Why Strong Social Institutions Are Needed to Survive Economic Growth. Washington DC: The Heritage Foundation.

CGIAR (Challenge Program on Water and Food) (2004). World Water Crisis—The Volta River Basin—Global Research Effort to Produce More Food with Less Water. http://www.waterforfood.org

Chambers, R. (1970). Introduction in the Volta Settlement Experience. London: Ed Chambers Pall Mall Press.

Durkheim, E. (1893). The Division of Labour in Society. New York: The Free Press.

Irvine, F. R. (1947). The Fishes and Fisheries of the Gold Coast. London: The Crown Agents for the Colonies.

Kpando (2005). Annual Reports, Kpando District Assembly.

Lenselink, M. N. (2002). Rural Development: Participation in Artisanal Improved Livelihood in Fisheries Management for West Africa. Fisheries Technical Paper FAO Corporate Document Repository \#432.

Masser, M. P. (1988). What Is Cage Culture? Stoneville, MS: Southern Regional Aquaculture Center (SRAC).

Max Weber (1971). As Cited in Webster Andrew (1988). Introduction to the Sociology of Development: Macmillan Education Ltd.

Mensah, M. A., Koranteng, K. A., Bortey, A., \& Yeboah, D. A. (2006). The State of World Fisheries from a Fishworker Perspective: The Ghanaian Situation. SAMUDRA Monograph, Chennai: International Collective in Support of Fishworkers (ICSF), 88.

Rogers, E. M. (1995). Diffusion of Innovations (4th ed.). New York: Free Press.

Senah, K. A. (1997). Money Be Man, the Popularity of Medicines in a Rural Ghanaian Community. Doctoral Thesis, Amsterdam: Academisch Proefschrift Universiteit Van Amsterdam, 104.

South Dayi (2006). Development Plan Report District Assembly.

Uwe, T., Groenewold, G., \& Marcoux, A. (2001). Demographic Change in Coastal Fishing Communities and Its Implications for Coastal Environment. Technical Paper No. 403, Rome: FAO.

World Bank (2004). Saving Fish and Fishers toward Sustainable and Equitable Governance of the Global Fishing. Sector Report Agriculture and Rural Development Department, Washington DC: World Bank. 
Scientific Research Publishing (SCIRP) is one of the largest Open Access journal publishers. It is currently publishing more than 200 open access, online, peer-reviewed journals covering a wide range of academic disciplines. SCIRP serves the worldwide academic communities and contributes to the progress and application of science with its publication.

Other selected journals from SCIRP are listed as below. Submit your manuscript to us via either submit@scirp.org or Online Submission Portal.
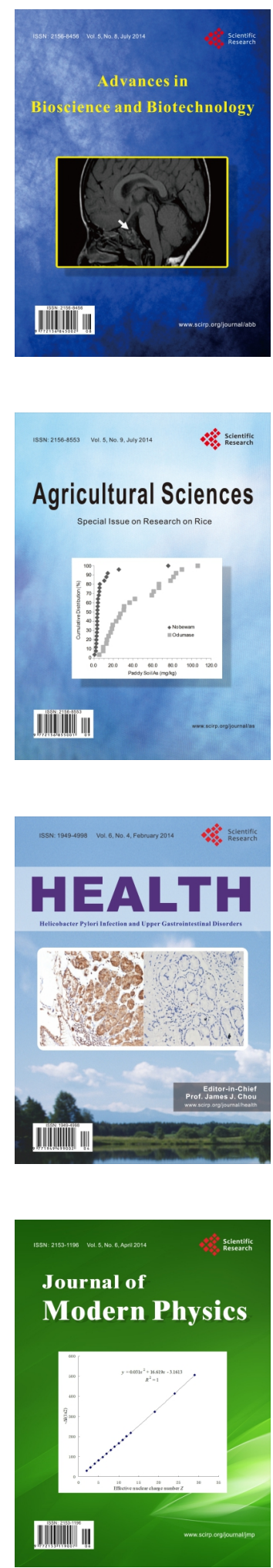
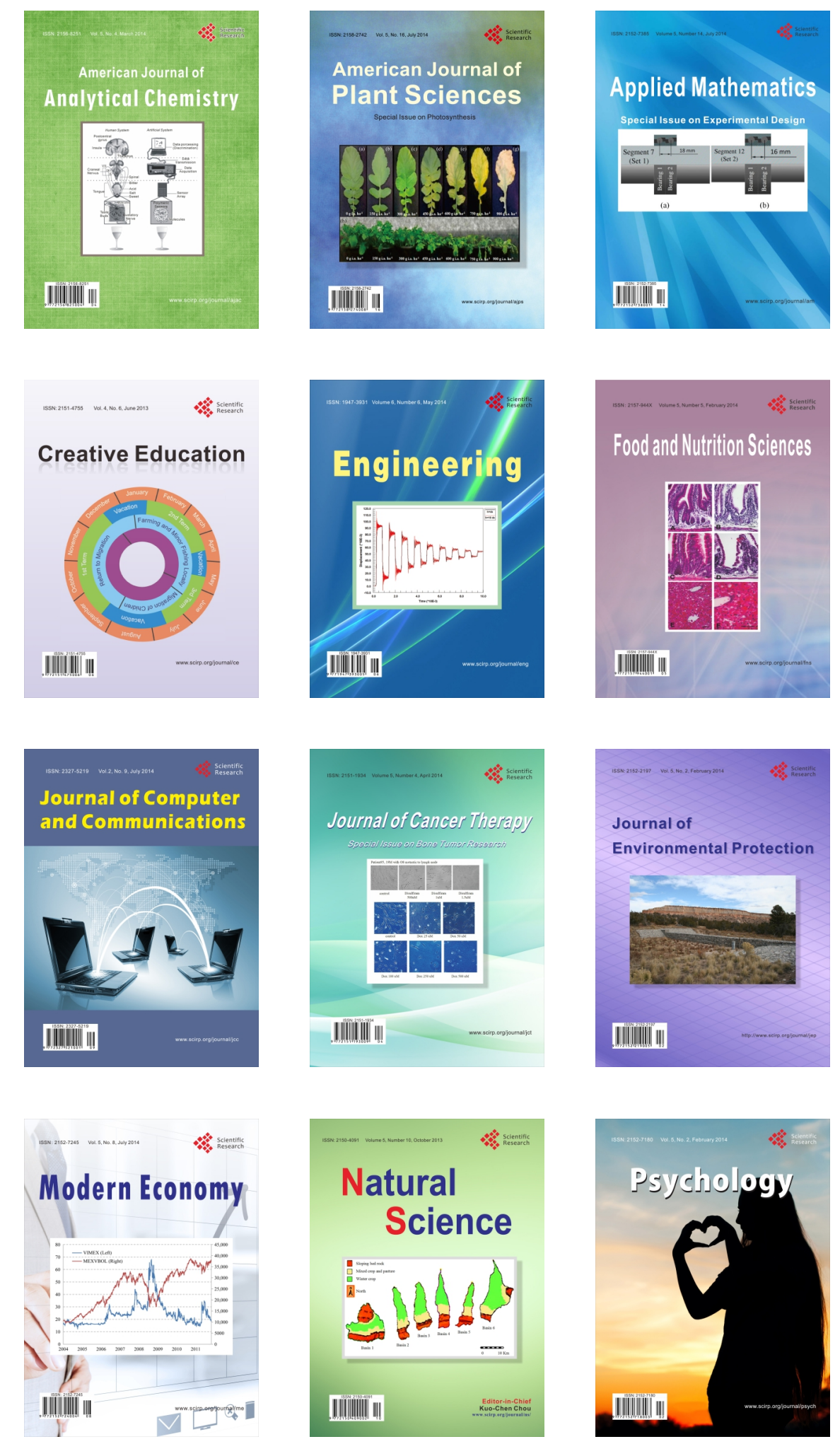